\title{
Discipline and Punish in the Humanities: A Philosophically Indisciplined Manifesto
}

\begin{abstract}
Advancing the notion of a methodless method, the author proposes an alternative to the quest for methods and methodologies, as an indisciplined perspective and approach, one that is impertinent, insolent and ironic. Using Paul Feyerabend's prosed anarchistic method and overviewing the philosophical roots in the thinking of Socrates, Nietzsche and Marx, the suggestion made here is that humanities research must be liberated from its disciplinary tendencies and open toward indisciplinarity.
\end{abstract}

Keywords: research methods, philosophy of science, anarchic method, indiscplinarity

The title of this paper is an obfuscated reference to Michel Foucault's Discipline and Punish: Birth of the Prison (1975/1979). First because I believe that research and knowledge in the humanities are imprisoned in a disciplinary confinement. Just as the French philosopher argued, indicating how the carceral system and the creation of mental asylums or boarding schools have "normalized" human society by coercion, my following arguments are based on the presupposition that academic research is trapped in coercive methodologies. Sometimes called "disciplinary silos" or "methodological silos" (Brannen and O'Connell 2015 271), the confinements of methods and research frameworks are hard to escape. While Foucault proved systematically that knowledge was administered through punishment in

\section{Doru POP}

Babeș-Bolyai University

doru.pop@ubbcluj.ro

EKPHRASIS, 1/2021

COUNTERDISCOURSES AND

COUNTERPUBlics IN CINEMA, ART, MEDIA AND LITERATURE pp. $10-25$

DOI: $10.24193 /$ ekphrasis. 25.2

Published First Online: June 21, 2021 
order to create a docile social body, a tamed version of our identities, in the Academia a similar "knowledge apparatus" is in place. It's rituals of punishment and practices of coercion are more discrete, yet nonetheless efficient. Academics are following "rituals of allegiance" (Foucault 137) and, although they do not obey a feudal Lord, they worship the Supreme Authority of the Scientific Method. Embracing "scientism" in the Humanities might be a side effect of the divide between the "hard disciplines" (Natural Sciences) and "soft disciplines" (Humanities and Arts). Often the academics in the "softer" domains are discredited for not being "real scientists," when they are not following clear rules or when they are not being systematic enough. The agents of the academic disciplinary task force are acting like a "scientific militia," with the guardians of methodologies and the surveyors of methods activating their retaliation power not by physical punishments, but through the invisible hand of the "disciplinary squads" of academia, imposing the mantra: formulate questions, find the evidence, elaborate answers.

At the other end of this initial reference is the very fact that my own paper opens with a reference to Foucault, which is symptomatic for the problems faced by our research approaches. According to the Times Higher Education Data, Michel Foucault is among the most cited authors in humanities - the list includes, among others, Derrida, Freud, Chomsky or Marx. This makes my contribution yet another paper adding to the pile of repetitive studies. And the blasphemy will continue later on as more references to Marx or Derrida will be made.

\section{Brief comments on the paradox of the creative and the disciplined research}

Some would argue that the humanities do not suffer from a lack of methods and methodologies today. From the traditional methods designed to "study" humanity and human society, which were developed by historians, to the arrival of the new and innovative disciplines of the nineteenth century demographic research, when sociological tools became more popular, every and each methodology newly discovered was adopted into the Humanities. For a while the discoveries in linguistics gave rise to more approaches, and then psychoanalysis became popular, competing with several other interpretative perspectives such as hermeneutics or semiotic. Afterwards ethnology and its offspring, anthropology, became the new innovators of research. Today they are supplemented with even newer approaches, with various ethnological practices, including digital images, while photography and video research were long ago integrated into the mainstream studies. The so-called "visual methods" were improved further with various technologies, allowing the research methods to move into the digital humanities era. The introduction of "shared research" in 
the intercultural and transdisciplinary studies (Haller and Zingerli 2020) together with the "data-intensive humanities" (Manovich 2012) are opening more horizons of research.

Other recent techniques, such as the so called "moving method" or "walking method" (O’Neill and Roberts 2020) are promising the revival of research by recuperating the peripatetic technique-although it was invented by Aristotle and practiced by the great philosopher himself in the long walks around the Lyceum, since he was not allowed to own land in Athens. Such innovative techniques are mixed with other practices specific to the "classical" qualitative approaches (life storytelling, ethnographic biographies, and other lived experiences). These are only a few of the attractive approaches advanced in the field of humanities, showing how easily adaptable the domain is, from the use of the new digital technologies, to the integration of unexpected practices. Tablets and smartphones and the use of other democratised tools made available by the Internet have helped create new domains, while others propose the creation of an entirely new paradigm of the "artistic research" (Hannula 2013), or even attempt to generate a more "aberrant nuptial” between science and "artistic practices" (Giudici and de Assis 2019).

It seems that the competition between the two research agendas-between the "hard sciences" having a monopoly on the "proper" methods, those considered quantitative and rigorous and based on "hard data" collection, and the so-called "soft" methods, with their techniques and practices of investigation specific to the qualitative approacheshas been for ever subdued. The arrival of the "multi-methods" or the "mixed methods" (Hesse-Biber 2010), allowing the crossing of disciplinary boundaries, created a research environment where the "Holy triad" (qualitative, quantitative and mixed methods approaches) exists in an idyllic harmony. With all this diversity of techniques, theories and methods, sometimes divergent, sometimes convergent, the humanities today seem to be in a better shape than ever. The critical evaluation of literature, cinema, television or advertising includes a plethora of approaches, easily available and quickly mixed in the paradigm called "interdisciplinary."

In fact this has become the most popular intellectual activity in contemporary academia. With many authors practicing one form or another of transdisciplinarity, hundreds of research projects are driven by the new catchphrases: interdisciplinarity, multidisciplinarity, transdisciplinarity. Considered by some academics as the perfect solution, offering the necessary legitimation for the revival of the human sciences, interdisciplinarity is often used as a popular solution for liberal arts research. Almost all universities have their particular interdisciplinary programs, where a motley of methods are juggled together.

As many have argued, higher education institutions can only benefit from interdisciplinarity, with researchers finding "new and synthetic" ways of creating knowledge (Jacobs 79). The interdisciplinary dialogues, the combining of various sciences otherwise segregated (like art history and economy, for example) and the overall openness are important. Since I do 
not intend to elaborate a map of methods and methodologies used in the humanities, I suggest taking a closer look at these innovative approaches. They are, one way or another, based on the same "disciplinary" attitude. Multi-disciplinary, inter-disciplinary, trans-disciplinary, cross-disciplinary, pluri-disciplinary, supra-disciplinary and even de-disciplinary solutions are simply replacing the methodological hegemony of one "discipline" (say quantitative research) with another monopoly, that of the "diverse" research practices. They often do no present new solutions; instead they represent more problems, especially when they are "prescribing" their own unique and adequate ways to be "innovative." While promising the necessary freedom for the dominion of traditional research, these methodological exercises generate new formalised discourses. If we understand by "method" any means to prescribe a particular mode of approaching knowledge, a preferred path to obtain "truth" or to "reach" desired answers (Paley 2017), then the meaning making processes, no matter how "subjective" or "creative," become "disciplined" and "coerced."

My own speculations were triggered by the false promise made by W. J. T. Mitchell in the "Introduction" to his seminal work, Picture Theory (1995 a), promising a liberation brought by visual studies. Free from the tyranny of "scientificity," Mitchell claimed that the boundaries of the discipline can be broken and that this "breakage" will produce a new "indiscipline." His form of rupture, that himself recognized to be an "anarchist attitude," one that came from "inside-out," was about to create a new choice in the interpretation of visual culture. However, this academic "indiscipline" was never fully developed by Mitchell, who in his works continued to practice a "convergence of disciplines." The daring "indiscipline" Mitchell anticipated (1995b 541) remains limited to the "incoherent" and "turbulent" manifestations of the visual culture. It was never fully developing and visual culture research today does not represent the "indisciplinary" field (542), so much anticipated. Mitchell, who supported a form of "disciplinary relaxation," nevertheless extremely important in the creation of the field of visual studies, elaborated on the categories of interdisciplinary approaches (top-down, bottom-up and inside-out) trying to deal with the methodological conundrums of this "theoretical indiscipline." Initially an extension of Feyerabend's suggestions about methodological diversity as a pathway to knowledge, it remained limited to the ability to go across existing disciplinary boundaries. However, a "methodological pluralism" cannot in and of itself provide access to knowledge. The kind of methodological freedom needed has to remove itself from this "pluralism." My argument here is that "theoretical indiscipline" can be practiced only when it is done as an instrument of an indisciplined mind. Thus, the philosophical indiscipline can generate the indisciplinary method.

My suggestion is not for yet another methodological relativism, nor am I making another programmatic call for a methodological anarchism, another nondisciplinarity or dedisciplinarization of the field. Ultimately I believe that the problem is not with the method or the methodology, but with the attitude, the mental predisposition by which knowledge 
is obtained. Before making my own appeal for a methodless method (rather an amethodical method, as in amethodos) and without claiming to have discovered yet another "magic" solution or a new methodology, we should explore once more a famous formula, advanced by Paul Feyerabend. What does it mean that "anything goes" in academic research?

\section{Indisciplining the undisciplined: the Dadaist and anarchistic method}

Paul Feyerabend was perhaps the most virulent contemporary critic of the "tyranny of science" (2011). Unfortunately, as he experienced in his personal life and career, adopting the "methodological heresy" and his schismatic views about the absolute truths of Science were severely punished by the Academic Panoptikon. In several lectures Feyerabend criticised the "totalitarian" predisposition of traditional research and denounced the absolutism of Reason. The "sanctions" for this impunity were not delayed. Labelled as an "anti-scientist" and an "irrationalist," the philosopher was marginalised and any reference to his opinions about the philosophy of science were quickly dismissed. Academic docility can be imposed in many ways and even if the burnings on stakes are no longer available, any divergence from the dogmas of "true science" are swiftly punished. The "unscientific" are ostracised and the predominant way of "doing science" is reinforced.

The success of the scientific method, which led to some of the most important developments in human society and technology, is not contested here. A revolution driven by the early empirical philosophers, with its accent on systematic research and the experimental method, has transformed our world. Undoubtedly "scientific progress," together with the "scientific method," based on structure, procedures, order and disciplined research, were beneficiary. However, when turned into a good for all recipe, the results are also negative. Adopted wholesale into many human sciences researches, pervading almost all the disciplines related to culture, art, literature and media, the tyranny of "scientific research" controls the outcomes of knowledge even today. Dominated by the demands for "scientific facts," "empirical data," and "objectivity," not allowing any questioning of the scientific theories and labelled as "fake," we are subjected to a kind of disciplinary terror.

Since Feyerabend's epistemology was widely discussed, debated and rejected, for the current argument I intend to return briefly to the problem of methodological anarchism. By expanding on the notion of "anarcho-dadaism," I am questioning if there can be a methodological answer to the problems raised in the Humanities. More importantly, we need to address if the simple revisitation of the "qualitative methods" is sufficient, with the particular relevance for my own field interest, that of visual culture studies and cinema research. 
With Feyerabend provocatively advancing the formula "anything goes," very appealing when confronted with the feeling that empiricism and the restrictions of the scientific method hinder creativity, this radical principle is based on a profound philosophical attitude. Feyerabend claims the need for questioning all dominant points of view and every generally accepted theory. The promise of methodological freedom from the dogmatic practices, together with the conceptual liberation from the tyranny of the "scientificity" or "objectivity" are thus preceded by rejecting the rules and restrictive methodologies, which are indeed inhibiting real progress of knowledge. More importantly, the development of new theories cannot be produced when researchers repeat the same mantras over and over again.

Some authors (Papineau 44-45) claim that the "anything goes" formula must not be understood as a free for all in the social sciences. It still means to follow preexisting rules, that is to adopt practices proved to be functional in a particular field. Unfortunately, in many cases, the research in humanities is conducted by simply mimicking the outer mechanics of either the "scientific method," thus maintaining at least the extraneous appearance of a "scientific" dimension, or other formalised schematic and mock-systematic techniques, that provide a "scientific" patina.

Feyerabend's (1975/1993) "anarchistic methodology" and his suggestions about the anarchic dimension of research are undermining such compromises. His key propositions, starting with the basic principle that no real discovery can be made without some form of anarchistic impulse, means the total rejection of the scientific method. The advancement of an "epistemological anarchism" or an "anarcho-dadaism" is more than a methodological revolution. Feyerabend took a philosophical stand, as argued in the opening salvos of Farewell to Reason (1987), against those who impose "Reason" as the only way of finding the "Truth." Our Western civilisation transformed "Reason" (together with rationality or objectivity) into a form of global hegemony (10). Anything else, in the academia and elsewhere, is labeled as "irrationality," "sloppiness" or, sometimes mildly, as "intuitionism."

Returning to the opening thesis of his 1975 manifesto against the scientific method and the proceeding methodologies, the observation that breaking the existing methodological precepts was always a fundamental way of discovery, the essence of real knowledge is incontrovertible. Using the case of Galileo for the refutation of the absolute truth of the scientific method also remains relevant. The famous Italian scientist did not need an "approved method" in order to achieve one of the greatest discoveries in the history of human knowledge. In fact, he was moving against the existing "facts" and the established "truths." Taking a stance against the "chauvinism" of existing knowledge is mandatory.

Comparing his epistemology with Dadaist exercises, which allowed a new generation of creativity and new ideas to be produced, Feyerabend acknowledged later in his autobiography and disclosed the mechanism of his philosophy by stating that his "anarchism" was based on the fact that he "loved to shock people" (1995 142). His "outrageous" articles and conferences, 
which transformed him into a pariah of the Academia, confronted the chauvinists and intolerants of the research universe, the inherent totalitarian attitude of intellectuals and university professors.

Without going deeper into the larger debate about the validity of the procedures (and dogmas) of the scientific method, I consider that the approach proposed by Feyerabend is relevant only when coupled with a philosophical attitude. My own methodological query is based on a similar counter-inductive mechanics, driven by going against established facts. Without resuming the entire history of science overviewed by Feyerabend, the reality is that none of our theories, either quantitative or qualitative, provide results without an irreverent thinking.

\section{When Plato laughed and Nietzsche cried: A short history of irreverence}

Let us consider that our profound problem with knowledge has to do more with the way in which our brains are wired and less with the methods we use to achieve that knowledge. As cognitive researcher Donald Hoffman (2019) demonstrated, our brains have evolved to produce specific operation modes, our mind is the result of a series of adaptations which allowed us to survive and to dominate our environments. Conversely, it has created a mindframe that allows our brains to construct a reality based on these assumptions that they constantly make about what we are experiencing. Thus, we have developed sets of ideas for everything, from the simplest perceptions of color, to the most complex phenomena of the mind. Basically the world that we see (or rather the world as we see it) can never be the "objective" world. This reality is the result of a natural selection process generating brain mechanisms which not only informs us about what it is "True," it also helps fit the world to our expectations and needs. This neuroscience researcher advanced a theorem named the "Fitness-Beats-Truth," a formula that contains the assumption that we are not made to function by knowing the truth, in fact we have evolved to do exactly the opposite, to ignore the truth even when it is right before our eyes.

In the history of humanity there were many great impertinents who looked for ways around this conditioning. Perhaps Alexander the Great remains one of most impetuous and irreverent characters, his exercise of cutting through the Gordian knot with his falcate remains an example of how to find solutions to apparently unreasonable problems. The problem of irreverence is even more complex in the history and the theory of knowledge. It reverberates in our discussion about methods and methodologies and, since one cannot deal with several millennia of philosophical thinking, I have selected three thinkers who have observed the effects of this problem and have provided solutions. 
One of the first is the father of European thinking, Socrates. Present through the dialogues written by Plato, who faithfully recorded the words of his great teacher, the model of knowledge and his method of understanding are bot easily discernible. This unbelievably influential ancient philosopher followed a famously paradoxical principle: "I know that I know nothing" (in Latin "scio me nescire"). This is the foundation of the Socratic method, sometimes identified with the more ancient elenchos (or elenchus, for the particular Socratic technique). Based on a systematic dismantling of the inconsistencies in the ideas and stereotypical opinions about the world expressed by his fellowmen, Socrates is often presented as a conversationalist. In fact Aristotle, the disciple of Plato, described his technique as syllogismos antiphaseos. In the "Posterior Analytics" (72a) Aristotle discussed the troublesome Platonic dialogue "Meno" and questioned further the issues we are also debating here-how do we know what we know? The Stagirite philosopher, teacher of Alexander the Great, describes technically the antiphasis as a contradiction technique, a pathway to discover the contradictions in the thinking of other people, broadly understood as a form of "cross-examination." This was clearly designed to expose the "conceit of knowledge" of the Socratic interlocutors (Vlastos 1982), yet the elenctic method is functioning not only inside the Socratic debate, it is a technique, a mode of thinking constantly prescribed, not only in the texts, but also in the pedagogical, social and political outcomes of the Socratic practice. Elenchos is more than a refutation technique or an argumentation methodology, it extends to life itself. Socrates was educating his disciples to a form of antiphastic attitude, contained by the dictum: "An unexamined life is not worth living," as announced in Plato's "Apology" (38a5-6), that is the critical "examination" of everything (of self and of others) as a practice of elenchus.

It is not my purpose here to insist on the issues of the Socratic methods, many authors have done a much more thorough investigation of these issues (more in Scott 2002). My argument here is that elenchos is basically a form of intellectual irreverence. The virtues and defects of the "indisciplined" mind can be found in the actions of the most beautiful and least serious of Socrate's pupils, Alcibiades. Acting like a true "Spitzenbube," a rascal and a social scoundrel, Alcibiades was accused, like his Master, of "impiety" (asebeia - $\dot{\sigma} \sigma \dot{\beta} \beta \varepsilon \iota \alpha$ ). Actually, Alcibiades demonstrates plentifully what it meant to be irreverent and impudent in the practical world. Taking a stance against the set of religious beliefs of his contemporaries, this "indisciplined" disciple enacted a public and practical manifestation of elenchos. With a total disrespect for social order and authority, which was the central accusation leading to the condemnation of Socrates himself, who clearly educated the Athenian young elites, of which Alcibiades was the most notorious, to be indisciplined means to disregard what others hold to be absolute.

I hold that asebeia must be practiced as a Spitzenbube method, always finding the fissures in the walls of beliefs and constantly dismantling any false claims. One of the pathways of 
irreverence is to invent ridiculous ideas, just to perplex the untrained minds. Ultimately this is the spell of Plato, one which I believe must be maintained intact. This is the foundation of the intellectual asebeia. The term, which for the ancient Greeks was defined as any criminal action, describes any blasphemous activity, any form of "desecration and mockery" (particularly of the divine representations), thus any form of "irreverence and disrespect" towards social rules, parents or the ancestors and their myths. In the Athenian legal system, where asebeia is clearly described as impiety, and the only form of punishment for impiety was death, there were many similar cases. It is relevant that, while the most notorious case of trial for asebeia was Socrates, another satirist, Aeschylus, was subjected to a similar process. The great tragedian was accused of divulging the secrets of the Mysteries in his plays, and was pardoned only because he claimed ignorance (since he was not an initiate), but mostly due to his remarkable services in the military during the battle of Marathon.

Socratic thinking, which was always unconventional, sometimes radical, but never conformist, is often misjudged and misinterpreted. One of the most infamous attacks pitted against Plato was made by Karl Popper (1945). He accused the disciple of Socrates for casting a negative "spell" on our civilisation and society, invoking Plato's role in the developing the Great Negative Idea of political totalitarianism (Popper 28), which made him the "enemy number one" of open society. I would suggest that what escaped Popper was the utter irony of the Platonic thinking. Had he read more carefully one of the most sarcastic dialogues in which Socrates interacts with the obtuse minded Euthyphro, where he deals with the issue of corrupting the youth of Athens, Popper could have avoided this misreading. Socrates (through Plato) invents an absurd story, one in which a son is accusing his father for a crime against a criminal he himself hired. The narrative is exemplary for the Socratic method. This must be understood not simply as a dialogical technique, nor just a pathway against narrowmindedness. It is an ironic and irreverent approach to knowledge. Clearly, the Socratic method is at work in his dialogues, where he exposes the fallacies of thinking of other people, thus making possible the access to real thoughts. With the help of irony, as previously noted by Vlastos (1987), the readers, together with the characters interacting with Socrates, can be made aware and can discover the real meanings of the world.

I would argue against Popper and support the claim that Plato was in fact a supporter of the open mindedness, and that he was actually following the Socratic principle to its ultimate conclusions. Among the infamous students of Socrates Alcibiades was not the worse. Often misunderstood as the "good" disciple, Plato was practicing a similar impudence like Alcibiades, only not practical, but philosophical. Not as simple-minded as Xenophon, Plato takes further the subversive thinking practices of Socrates, following a methodological Spitzenbube attitude, an indisciplinary approach to knowledge. While Alcibiades was guilty for performing a material profanation (of the statues), by disrespecting religious and civic rituals, Plato is practicing a philosophical form of profanation. Deeply 
hidden into the dialogues, the Platonic irony is systematic and it goes far beyond the "ironic mode" attributed to his Master. Actually, as demonstrated by David Grene (1950), there are no "Platonic ideas" in Plato's dialogues, his auctorial voice is never heard and there are no interpretative instruments to guide us into what his opinions are and what belongs to Socrates. Remarkably, in his letters, quoted by Grene (107), he confirms that "none of the dialogues are mine." All the distinctions between Socratism and Platonism were made later by philologists, discerning between various sources, thus Platonic irony can easily escape us, since even the Greek concept of eirôneia is related to concealment.

Let us consider, together with Socrates, who expressed in Phaedrus (244a) that "the greatest blessings come by way of madness," that most of what we consider to be "serious" in the Platonic ideas are forms of ironic entrapments. No wonder that many have fallen into the intellectual traps set by Platon, from J. A. Stewart who published in 1905 a scholarly interpretation of the Platonic myths, which he considered to be "fundamental conditions of conduct and knowledge" (2), to Jacques Derrida. It is easy to fall under the "spell of Plato," yet not in the sense pharmakon attributed by Derrida (119) in his deconstructive interpretation. While the Derridean intuition of associating Plato with deceit is valid, the subvertion of the common opinion that Plato's ideas were "serious" is more difficult. Derrida's reading of Platonic mythologemes as pharmakoi must be taken to its ultimate conclusion. The creation of invented myths and mythological characters is one of the most important instruments in Plato's dialogues. Like the myth of the cave, often cited as a serious story, which is an ironic Platonic invention, or the myth of Theuth, described by Plato in Phedrus as total mockery not only of the "father of letters" (with the ironic claim that writing encourages forgetfulness), but also that of the common belief in "old stories," one of the ironic figures on this list must be Diotima. Socrates, who amusedly claims that she taught him philosophy, uses a woman as instructor, to the horror of the Athenians of his time. More shocking is the fact that she was a priestess of whom nobody has ever heard about and she was from Mantineia, at that time an ally of the Spartans. Finally, another example for this mechanism is the construction of the story of Atlantis, which we are still searching for and trying to explain today, although it is clearly an amused mythological absurdity. This missing city, described to be "larger than Asia," with walls made out of an inexistent metal (the fabled "Orichalcum," a Platonic unobtainium), is only a dialectical irony designed to make the readers think.

Friedrich Nietzsche, although a sworn enemy of Socrates, was practicing a similar reversed subversion. The German philosopher was an anti-disciple of Socrates, an actual philosophical Alcibiades who was ultimately practicing a Socratic method, which made him one of the most radical thinkers in Western philosophy. A master of the indisciplined mind, Nietzsche looked into the society of his time and activated the mechanisms of utter impudence and insolence. Often identified as a "rhetoric of nihilism" (Darby et al. 1989), he was practicing a form of radicalism that was based on an anti-phrastic thought process. Denouncing Socrates 
as the "destroyer of tragedy," the young philosopher (who was only 28 when he wrote The Birth of Tragedy) was in fact enacting a typical elenchos mechanism. By destroying the statues of the "evil dwarf," whom he considered to be guilty of infecting European civilisation, he was practicing a type of outrageous thinking that must have been a total monstrosity for his contemporaries, just as Socrates was able to induce in ancient Athens. Without insisting here on the ambivalence of Nietzsche's relationship with the ancient philosopher, nor his contribution to the psychoanalytical theory (Lehrer 1995), there is an ambivalence between Nietzsche's attack on Socrates and his fundamentally Socratic method. Even when he is most radically denouncing Socrates, like in the The Twilight of the Idols, where he goes on an all-out war against the "ugly" and "plebeian" Greek philosopher, describing him as nothing more than a "buffoon," affected by a form of retardation produced by interbreeding, or in the Birth of Tragedy where he is denouncing the Socratic monstrosity, he is actually reverse mirroring the Socratic ideas in order to give shape to his own concepts.

This is repeatedly done in what can be considered the "Nietzschean method," a critique and a methodology resulting from anti-phrastic thinking. His dialectics, and in fact his entire philosophy, are forms of irreverence, unrestrained manifestations of antithetical attitude. For the purpose of this argument I am defining the anti-phrase as a technique, a method which, when used in a programmatic way, automatically generates new meanings. As a professional negator, often simplistically described as nihilist, the German philosopher practiced a form of powerful dialectics that allowed him to wage an intellectual war on all the pre-established ideas of his time. Using the anti-phrase to criticise Judaeo-Christian thinking ("Not contentedness, but power; not peace, but war; not virtue, but prowess"), he took the mechanics of subversion to their utter consequences. Through the subversion of the existing values, for example by opposing the "spirit of scientific knowledge" which destroyed "myth," he arrives to the discovery of new ideas and values. This is explicit in the proposed "rebirth of tragedy," where he is suggesting the replacement of the "old" with a new triad (Delusion, Will, and Woe) he is elaborating, an anti-phrase to the previously identified Socratic decadence. Nietzsche's critical method and methodology was, as noted by Karl Jaspers (1969), a result of his thinking based on the desire to "shatter idols" (54). This he does systematically (while claiming anti-systematic freedom). In Beyond Good and Evil, the Genealogy of Morals, The Antichrist, or Thus Spoke Zarathustra, Nietzsche activates the anti-phrase.

Nietzsches's unbounded negation and his cutting dialectic would be inconceivable in our contemporary society. When polemics, contradictions and dissent are often silenced and denounced as "politically incorrect," his observation would be difficult to make. Yet it is in this "difference," in the fundamental contradiction and negation of the truths believed to be self-evident that the essence of thinking relies. No matter if one agrees or not with his speculations and vicious diatribes, it would be important to recognize and acknowledge 
how the Nietzschean thought processes functioned. If morality, dialectic, and theory "killed" tragedy, then another form of instinctive wisdom must replace them. Of course, what he considered to be "the blessed hopes for the German character" had unexpected consequences. When the "liberation" of the German mind from "moderation, democracy and modern ideas" was achieved, it produced tragedy indeed. This is when Nietzsche cries, not like in Irwin Yalom's novel embracing a beaten horse in Turin, but weeping as the last man of humanity (as "Letzter Mensch").

\section{Turning things upside down: In the defense of Marx (and subconsciously of Freud)}

Karl Popper took another punch against two other authors he disregarded and utterly despised for their creation of what he calls "unacceptable" sciences. Denouncing both Marx and Freud as frauds and stating that their theories are untestable and not provable, Popper labels bot Marxism and Freudian psychoanalysis as pseudoscience. Their basic propositions were "unfalsifiable," thus methodologically indefensible. Marxism, psychoanalysis and astrology were comparably the same since they all use "prophecy" disguised as a "scientific interpretation" of society and economy. The entire volume 2 of The Open Society and its Enemies is dedicated to these attacks against these approaches, yet Popper himself agrees that what we call "method" in any science is basically a form of criticism. Nevertheless, while in his remarks on Marx in the second volume of The Open Society and Its Enemies Popper (78) acknowledges that the father of communism was open-minded, a sincere and a true enemy of intellectual phariseeism, he cannot pardon his trust in the Hegelian dialectics.

Yet Popper knew very well, as Lenin pointed out before him, that it would be impossible to understand Marx without comprehending the method advanced by Hegel's Logic. Marx himself explained that his own method was basically a reverted form of the Hegelian method, a dialectics "standing on its head." In my own understanding, the basis of any amethodical method is its ability to turn upside down the existing knowledge. The subtitle of Das Kapital, which was "a critical analysis of capitalist production," stands witness for the mechanisms of Marx's thinking. Marx believed that he could read into the manifestations of the present and anticipate the future. If in capitalist society labour was exploited, then, by simple reversal, the transformation of human life was possible by the destruction of these conditions. I realize this means to oversimplify the arguments, but basically the method employed by Marx was to invert already existing situations and to find new ways of understanding society and the world. The result was that Marx, as noted by Jameson (1974), was practicing a dialectical reversal, a form of paradoxical turning around of a phenomenon into its opposite (309). Starting with the revelatory reversal of Hegel, turning upside down his dialectics into the 
Marxist method, later described as a materialist dialectic, he enacts a reaction against the "idealist dialectics" dominant in his time, Marx continuously practiced this reversal.

Unfortunately, as many Marxist and Post-Marxist approaches became "disciplinary," even those broadly defined as reflexive and post-structuralist (including the post-colonial and feminist), they have entered their own vicious circle of repetition, where the recirculation of the same (objectification, racialization, decolonization) does not allow any new knowledge.

We must also argue, together with Elster (1986), that Marx was not only developing a political-economical methodology, as he was practicing a critical philosophical method. One of his remarkable lessons is the ability to be a critical and acid writer. He often mocks the "solemn schoolboys" who write and speak in stereotypes, laughing about the "German literati" and the philistines of his time. Thoroughly analyzed by Thomas Kemple (1995), parody remains one of the preferred instruments of the father of dialectical materialism. Marx developed his own form of "gnawing criticism" and used the pamphlet format to attack anything he considered to be dogmatic. Often mocking even his good friend Engels, who unfortunately was one of the first to turn him into a "dogma," process continued by the Stalinists who integrated his quips into mainstream thinking, even his writing style was that of elaborating "critical comments" on the side of each readings he made. Of course, the "critical" dimension of the critical method is many times limited to the ideological interpretation and, without questioning the utility of identifying racial or gender stereotypes in visual contents or media representations, the criticism becomes a repetitive and empty tool.

Ultimately, the amethodical approach is what Marx anticipated, a point in which the natural sciences and the human sciences will become incorporated into a single science, a true "science of man," overcoming the ill adjusted forms of "alienated science" (Marx 1967). To paraphrase Marx once more, an indisciplined scientist can dabble in the morning with Socrates and ancient philosophy, can fish in the afternoon in the ponds of contemporary popular culture and later hunt in the dense forests of critical theory.

\section{Against the fear of the conceptual penis}

So what is indisciplined thinking? Do I propose a return to Socrates, Nietzsche and Marx, in a strange drag show of philosophers? Is this another call for interdisciplinary approaches, a "methodological croc-pot" where anything goes with everything, in an endless mixing of all things possible?

First I think we need to accept that "indiscipline" must be practiced as a form of scientific amateurism, in the sense described by Andy Merrifield (2017), pushing against the regime of expertise that was created by modernity. Our lives and knowledge are too much dominated by "bean counters and rule followers," we need a kind of methodology that does not shy away 
from the study of culture that can be practiced with the help of quantum physics principles. Of course, multidisciplinarity should not be practiced as a full-contact sports, a form of academic pentathlon in which the able competitors shoot with philosophy, neurolinguistics, and any other weapon they find lying around in the empty fields of humanities. This is not an arena for showing a mix-and-match prowess, as in the case of James Lindsay and Peter Boghossian who published the infamous paper about "the conceptual penis." This new academic hoax, in the style of the Sokal affair, which tried to expose the scientific inconsistency of the humanities (with the creation of "grievance studies") exposes the risks of fashionable nonsense.

Of course, this is the typical approach in several visual culture and media studies domains, where a combination of structuralism, semiotics, psychoanalysis, feminism and a dash of cultural studies is recommended (Benshoff 2016). Either used as a separate methodology or in the "mixed methods" version, these theories can generate a modest repetition of the same results. Since I am myself a practitioner of some of these methods, I must perform an implicit self-criticism by deeply questioning the relevance of mirroring over and over the same observations and concepts.

A possible response to this issue is borrowed from Rosi Braidotti (1994), who used the notion of nomadism and practiced nomadology as a form of intellectual freedom. Her claim that thinking itself is nomadic and that philosophical thought should display the signs of structural nomadism is not only denouncing rationality and recovering the "vitalist" ideas already promoted by Bergson, but she is inspired by Deleuze and the "ecological ethics" model, one which can be used "to create transversal links between the categories" (114-15) that are otherwise disconnected. The method of nomadism is "transversality," where not only aesthetics or ethics can be brought together, but also various heterogeneous scientific domains, such as art and genomics. The central benefit of nomadism is that, while using critique as a central tool, it also practices a form of destabilizing attitude, a criticism pitted against every existing order or power. As Braidotti (127) acknowledged, when any method or approach (as is the case with feminism) becomes an established discipline, perfectly integrated into the mainstream academia, many authors trying to maintain their hard earned positions, the resources of the method are exhausted.

An indisciplined perspective and approach must also be impertinent and insolent. Irony must remain one of the main ingredients for any indisciplinary methodology. As previously noted, this "style of inquiry," practiced by Plato and Marx in remarkable fashions, must be used against conventions and rules, undermining any and all the stereotypes. The indisciplined method is amethodical because it must be subversive against its own foundations; it should be manifested as a thinking subverting its thinking mechanisms. This is not such an utter novelty. Gaston Bachelard, in his concluding remarks about the true "spirit of science" 
(1938), noted that we must be able to "think against the brain," since our own brains work as an obstacle to scientific thought, because it is used for banal activities (248). The capacity to reach uneasy conclusions, by a critical evaluation of our own ideas, the challenging of biased thought, this is the foundation of an indisciplined approach.

My argument here is that we should not be searching for "new methodological tools," instead we should activate the indisciplined mode of thinking, and it will take each and everyone of us to new methodologies and instruments of finding knowledge.

\section{Works Cited}

BACHELARD, Gaston. La formation de l'esprit scientifique: Contribution à une psychanalyse de la connaissance objective. Vrin, 1938.

BENSHOFF, Harry M. Film and Television Analysis: An Introduction to Methods, Theories, and Approaches. Routledge, 2016.

BRAIDOTTI, Rosi. Nomadic Subjects: Embodiment and Sexual Difference in Contemporary Feminist Theory. Columbia University Press, 1994.

BRANNEN, Julia and Rebecca O'Connell. "Data Analysis I: Overview of Data Analysis Strategies," in Nagy Hesse-Biber, Sharlene and R. Burke Johnson (eds.), The Oxford Handbook of Multimethod and Mixed Methods Research Inquiry. Oxford University Press, 2015.

DARBY, Tom et al. (eds.). Nietzsche and the Rhetoric of Nibilism: Essays on Interpretation, Language and Politics. Carleton University Press, 1989.

DERRIDA, Jacques. Specters of Marx: The State of the Debt, the Work of Mourning, and the New International. Routledge, 1994.

---. Dissemination. Translated by Barbara Johnson. University of Chicago Press, 1981.

ELSTER, John. "Marxist Methodology," in Elster, John (ed.), Karl Marx: A Reader. Press Syndicate of the University of Cambridge, 1986, pp. 1-28.

FEYERABEND, Paul. Against Method: Outline of an Anarchistic Theory of Knowledge. Verso, 1993 (first edition 1975).

---. Science in a Free Society. New Left Books, 1978.

---. Farewell to Reason. Verso, 1987.

---. Killing Time: The Autobiography of Paul Feyerabend. University of Chicago Press, 1995.

---. The Tyranny of Science. Edited by Eric Oberheim, Polity Press, 2011.

FOUCAULT, Michel. Discipline and Punish: The Birth of the Prison. Vintage Books, 1979 (first French edition 1975).

GIUDICI, Paolo and Paulo de Assis (eds.), Aberrant Nuptials: Deleuze and Artistic Research 2. Leuven University Press, 2019.

GRENE, David. Man in His Pride: A Study in the Political Philosophy of Thucydides and Plato. University of Chicago Press, 1950. 
HALLER, Tobias and Claudia Zingerli. Towards Shared Research: Participatory and Integrative Approaches in Researching African Environments. Transcript Verlag, 2020.

HANNULA, Mika. Artists as Researchers: A New Paradigm for Art Education in Europe. Academy of Fine Arts, 2013.

HESSE-BIBER, Sharlene Nagy. Mixed Methods Research: Merging Theory with Practice. Guilford Press, 2010.

HOFFMAN, Donald. The Case Against Reality: Why Evolution Hid the Truth from Our Eyes. W. W. Norton \& Company, 2019.

JACOBS, Jerry A. In Defense of Disciplines: Interdisciplinarity and Specialization in the Research University. University Of Chicago Press, 2014.

JAMESON, Fredric. Marxism and Form: Twentieth-Century Dialectical Theories of Literature. Princeton University Press, 1974.

JASPERS, Karl. Nietzsche: An Introduction to the Understanding of His Philosopbical Activity. Regnery Pub, 1969.

KEMPLE, Thomas M. Reading Marx Writing: Melodrama, the Market, and the "Grundrisse". Stanford University Press, 1995.

LEHRER, Ronald. Nietzsche's Presence in Freud's Life and Thought: On the Origins of a Psychology of Dynamic Unconscious Mental Functioning. State University of New York Press, 1995.

MANOVICH, Lev. "Trending: The Promises and the Challenges of Big Social Data," in Matthew K. Gold (ed.), Debates in the Digital Humanities. University of Minnesota Press, 2012, pp. 460-75.

MARX, Karl. Economic and Philosophic Manuscripts of 1844. Progress, 1967.

MERRIFIELD, Andy. The Amateur: The Pleasures of Doing What You Love. Verso, 2017.

MITCHELL, W. J. T. Picture Theory: Essays on Verbal and Visual Representation. University of Chicago Press, 1995 a.

---. "Interdisciplinarity and Visual Culture," Art Bulletin, December, 1995 b.

O'NEILL, Maggie and Brian Roberts. Research on the Move. Routledge 2020.

PALEY, John. Phenomenology As Qualitative Research: A Critical Analysis of Meaning Attribution. Routledge, 2017.

PAPINEAU, David. For Science in the Social Sciences. Macmillian, 1978.

PLATO. Plato in Twelve Volumes, Vol. 1 translated by Harold North Fowler; introduction by W. R. M. Lamb. Cambridge, MA, Harvard University Press; London, William Heinemann Ltd., 1966. Available online https://www.perseus.tufts.edu/hopper.

POPPER, Karl. R. The Open Society and Its Enemies. The Spell of Plato, volume 1. George Routledge \& Sons, 1945 .

---. The Open Society and Its Enemies. The High Tide of Prophecy: Hegel, Marx and the Aftermath, volume 2. George Routledge \& Sons, 1945.

SCOTT, Gary Alan (ed.). Does Socrates Have a Method?: Rethinking the Elenchus in Plato's Dialogues and Beyond. Pennsylvania State University, 2002.

VLASTOS, Gregory. "Socratic Irony”. The Classical Quarterly, 37(01), 79, 1987.

---. "The Socratic Elenchus”. The Journal of Philosophy, 79(11), 711, 1982. 